\title{
Regional evolution of mechanical dyssynchrony in a closed-chest porcine model of myocardial infarction as assessed by cardiac
} magnetic resonance

\author{
Miguel Santaularia Tomas*, Khaled Z Abd-Elmoniem, Tetsuo Sasano, Evert- \\ jan Vonken, Amr Youssef, Matthias Stuber, Harsh Agarwal, \\ Sahar Soleimanifard, Eduardo Marbán, Jerry L Prince, Theodore P Abraham \\ and Roselle Abraham
}

Address: Johns Hopkins, Baltimore, MD, USA

* Corresponding author

from 13th Annual SCMR Scientific Sessions

Phoenix, AZ, USA. 21-24 January 2010

Published: 21 January 2010

Journal of Cardiovascular Magnetic Resonance 2010, I2(Suppl I):P59 doi:10.I I86/I532-429X-12-SI-P59

This abstract is available from: http://jcmr-online.com/content//2/SI/P59

(C) 2010 Tomas et al; licensee BioMed Central Ltd.

\section{Introduction}

Mechanical dyssynchrony in the setting of an acute myocardial infarction (MI) is associated with adverse left ventricular remodeling and increased mortality.

\section{Purpose}

We investigate the relationship between dyssynchrony and infarct location and their evolution over time in a closed-chest porcine model of MI.

\section{Methods}

In six pigs, cine, late gadolinium enhancement, and tagged cardiac magnetic resonance imaging were performed at baseline (before MI) and early (10 \pm 2 days) and late ( $34 \pm 10$ days) after balloon induced occlusionreperfusion myocardial injury. Infarct, peri-infarct, and remote normal regions were defined as previously described. Cardiac morphology, function, location and extent of MI, and regional mechanics (circumferential strain $(\varepsilon C)$ ) were measured.

\section{Results}

Baseline ejection fraction (52 $\pm 5 \%)$ was significantly reduced both early $(44 \pm 7 \%)$ and late $(45 \pm 4 \%)$ post MI ( $p<0.01$ ). Delayed enhancement was $\sim 20 \%$ of LV mass and peak $\varepsilon \mathrm{C}$ was significantly reduced in MI segments (before $-26 \pm 4$, early $-10 \pm 7$, late $-9 \pm 7 \%$; $<<0.001$ ) and peri-MI (before $-24 \pm 6$, early $-19 \pm 6$, late $-17 \pm 4 \%$; $p<$ $0.001)$. Dyssynchrony index increased from $29 \mathrm{~ms}$ at baseline to $65 \mathrm{~ms}$ at early $(\mathrm{p}=0.007)$ and $98 \mathrm{~ms}(\mathrm{p}=$ $0.002)$ at late post-MI. Inter-segmental mechanical delay between peri-MI and MI versus normal segments at early post-MI stage were $23 \pm 36 \mathrm{~ms}$ and $118 \pm 58 \mathrm{~ms}$, respectively ( $\mathrm{p}<0.0001)$. Delays between peri-MI and MI segments versus normal segments in late post-MI stage were $9 \pm 12$ and $122 \pm 14 \mathrm{~ms}$, respectively.

\section{Conclusion}

Mechanical dyssynchrony occurs early after acute MI and does not worsen with time despite further reduction in regional function. Delayed mechanical activation is restricted to MI segments and does not persist in peri-MI segments. 